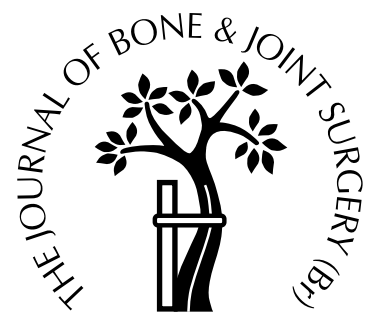

\title{
Tuberculosis of the foot
}

\author{
R. Mittal, V. Gupta, S. Rastogi \\ From the All India Institute of Medical Sciences, New Delhi, India
}

$I^{\mathrm{n}}$ n 44 patients with tuberculosis of the foot we identified five radiological patterns of lesions; cystic, rheumatoid, subperiosteal, kissing and spina ventosa. Cystic destruction had the best outcome and rheumatoid the poorest. All the patients were cured after antituberculous treatment for 18 months, and none required surgery.

J Bone Joint Surg [Br] 1999;81-B:997-1000.

Received 15 February 1999; Accepted after revision 23 March 1999

Tuberculosis has been known to mankind since the dawn of human civilisation but still remains a major problem in India and the developing world. Bones and joints are involved in $1 \%$ to $3 \%$ of all cases ${ }^{1}$ and about $10 \%$ of osteoarticular tuberculosis affects the foot. ${ }^{1-3}$ Although there is extensive literature on osteoarticular tuberculosis, there have been few studies on the involvement of the foot.

\section{Patients and Methods}

Between January 1994 and December 1996 we treated 44 immunocompetent patients who had tuberculous infection of the foot. Seven had a soft-tissue infection only and 37 had lesions in bone. Of the latter, there were 20 women and 17 men whose age range was from four to 63 years, with most aged between 25 and 40 years. Five had discharging sinuses at the time of presentation, but none had active pulmonary disease.

All the patients with only a soft-tissue lesion had a biopsy for confirmation, but those with bone lesions did not undergo this, and their diagnosis was based on clinical and radiological features.

The treatment for all patients began with a fourdrug regimen using rifampicin, isoniazid, ethambutol and

R. Mittal, MS Orth, Assistant Professor

V. Gupta, MS Orth, Senior Resident

S. Rastogi, MS Orth, Additional Professor

Department of Orthopaedic Surgery, All India Institute of Medical Scien-

ces, Ansari Nagar, New Delhi 110029, India.

Correspondence should be sent to Dr R. Mittal.

(C)1999 British Editorial Society of Bone and Joint Surgery 0301-620X/99/69925\$2.00

VOL. 81-B, No. 6, NOVEMBER 1999 pyrazinamide for two months, followed by rifampicin and isoniazid for 16 months. Each received $10 \mathrm{mg}$ of pyridoxine daily. The patients were followed up by plain radiography, with haematological and liver-function tests every three months during treatment. After completion of their drug regime, they were reviewed twice at intervals of six months. In those in whom weight-bearing was very painful, walking with crutches, avoiding taking weight on the affected foot, was advised.

\section{Results}

The calcaneum was the most common bone involved, and in 14 patients, two or more bones were affected. Lesions were present in the calcaneum in 17 patients, the metatarsals in 18, the phalanges in 15 and the osteotarsal bones in 12. We observed five patterns of bone lesions:

Cystic. This type of lesion, as seen in the calcaneum, had a well-defined radiolucent area with loss of trabeculae in the middle of the bone, but no sequestrum (Fig. 1a); when found in other bones it was often associated with a sequestrum (Fig. 1b). Cystic lesions were seen in 15 patients.

Rheumatoid. This was seen in the midfoot of ten patients. There was a loss of articular cartilage and osteoporosis of all the tarsal bones, except the talus and the calcaneum, giving the appearance of a coalesced mass of bone, similar to the lesions seen in the carpus in rheumatoid arthritis (carpal coalition) (Fig. 2). Infection in the midfoot spread rapidly to many joints because of their intercommunicating synovial spaces.

Subperiosteal. In seven of our patients subperiosteal scalloping of bone was seen on the lateral surface of the cuboid, the base of the fifth metatarsal and the head of the talus (Fig. 3).

Kissing. In four patients the infection was localised to one joint and symmetrical scalloped lesions had developed on the adjacent articular surfaces of the bones (Fig. 4).

Spina ventosa. Spina ventosa, which occurs in short tubular bones especially in childhood, was present in one patient. There was a spindle-shaped expansion with successive layers of periosteal new bone (Fig. 5).

A periosteal reaction was seen only in the metatarsals and phalanges, and in the presence of sinus formation. Localised osteoporosis was common. Soft-tissue swelling 


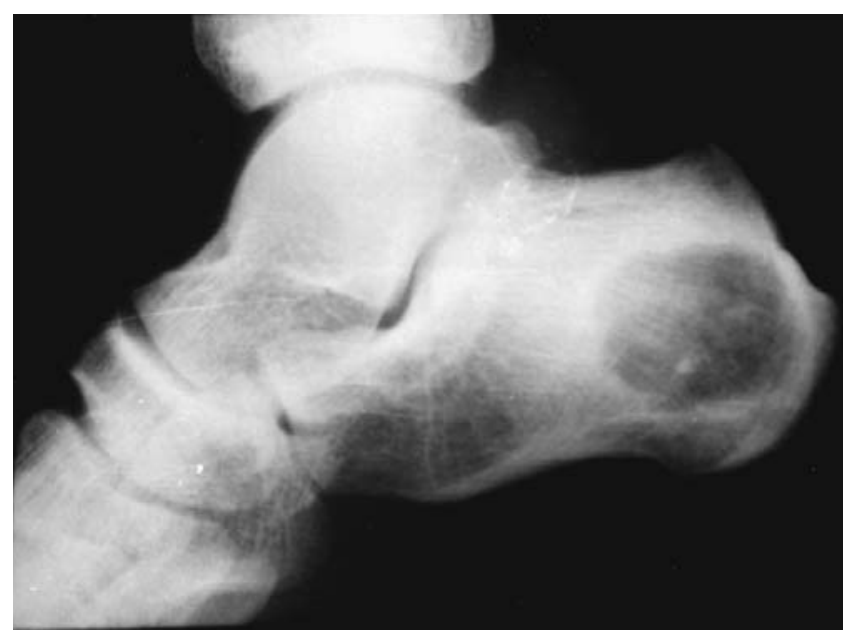

Fig. 1a

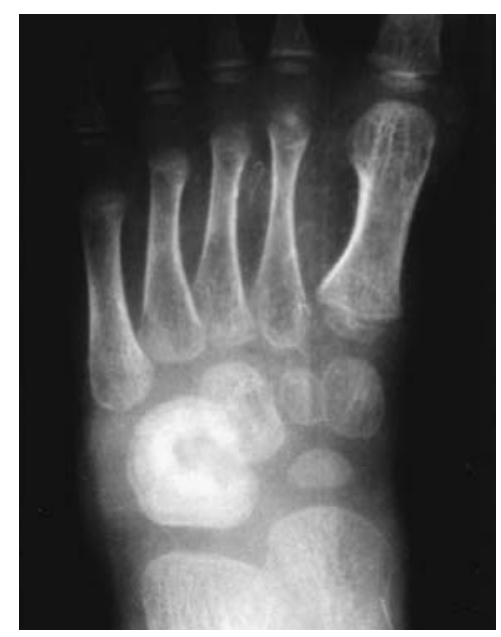

Fig. 1b

Radiographs showing a cystic lesion a) without a sequestrum in the body of the calcaneum and b) with a sequestrum in the cuboid.

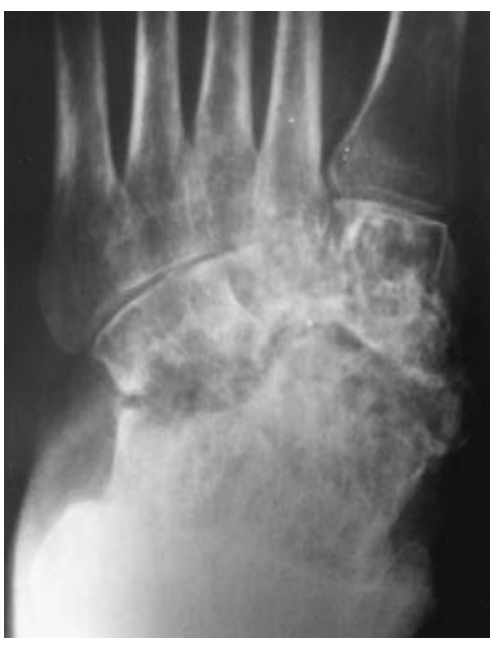

Fig. 2

Radiograph showing a rheumatoid type of lesion in the midfoot.

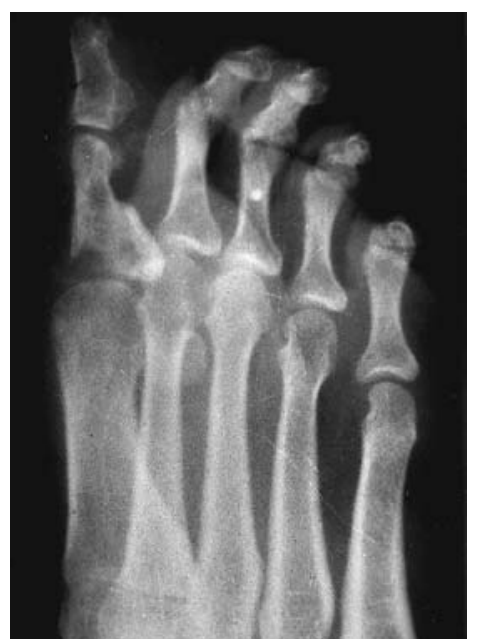

Fig. 3

Radiograph showing a subperiosteal lesion in the first proximal phalanx.

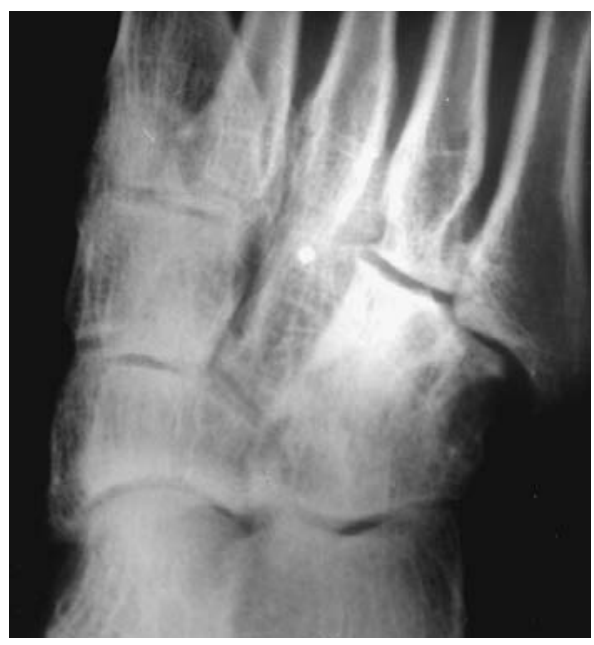

Fig. 4

Radiograph showing a kissing type of lesion involving the cuboid and the base of the fifth metatarsal. associated with osseous lesions was slight, probably because the bones of the foot are covered by tendons and tight fascial sheaths which resist distension.

Clinical signs of healing included a decrease in pain and swelling, disappearance of sinuses, improvement in gait and gain in body-weight. They were evident in most patients as early as five weeks. Radiological features of 'healing' were seen after four to five months of treatment.

At the end of treatment all discharging sinuses had healed. No patient had toxicity or resistance to antituberculous drugs and none required surgical intervention.

\section{Discussion}

The spine and hip are the most common sites of osteoarticular tuberculosis. It is most easily diagnosed in these areas. ${ }^{4}$ By contrast, tuberculosis of the foot and ankle is less common and is detected at a more advanced stage. ${ }^{3}$ Any of the joints of the foot can be affected either alone or in combination, but the midtarsal joints are the most common site. ${ }^{3}$ The bones involved are usually the calcaneum, talus, first metatarsal, navicular and medial and intermediate cuneiforms. ${ }^{1}$ The symptoms are those usually seen in musculoskeletal disorders; pain, stiffness, and swelling ${ }^{5}$ of the foot. There is, characteristically, early muscle atrophy. ${ }^{5}$ The significance of a history of trauma, reported by onethird of patients, is unknown. The ESR is almost always elevated in patients with tuberculosis. ${ }_{7-9}^{2,46}$ Pulmonary involvement is uncommon. ${ }^{7-9}$

Osteoarticular tuberculosis is a paucibacillary lesion and it is difficult to demonstrate or culture acid-fast mycobacteria from these lesions. In endemic regions, the clinical features, radiological appearance and elevated ESR are suf- 


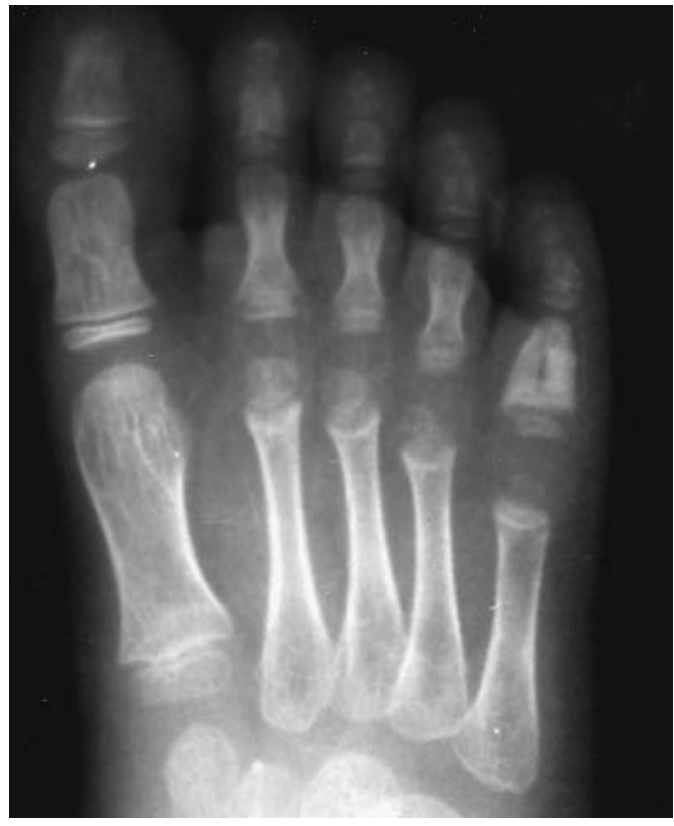

Fig. 5

Radiograph showing thickening and sclerosis of the fifth proximal phalanx - a spina ventosa.

ficient to diagnose tuberculosis ${ }^{10}$ and begin treatment. Although biopsy is indicated only in doubtful cases, in regions where tuberculosis is not endemic, histopathological or microbiological confirmation should be mandatory.

Imaging studies play a critical part in the diagnosis of tuberculosis of bones and joints. On plain radiographs the earliest changes may be erosions at the peripheral margins of a joint. ${ }^{11}$ MRI can demonstrate lesions in and adjacent to bone before they are evident on plain radiography. Periarticular osteoporosis occurs because of disuse atrophy and the direct action of toxins. The 'joint space' may be preserved since it can take a considerable time for enough destruction of cartilage to occur to cause radiological narrowing. ${ }^{12}$ Phemister's triad of periarticular osteoporosis, marginal erosions and narrowing of the joint space is the radiological feature of osteoarticular tuberculosis. ${ }^{13}$ Formation of a sequestrum may occur. If present, sequestra are small and few in number. ${ }^{1}$ The radiological appearances of rheumatoid arthritis, particularly when monoarticular, osteoarthritis, gout, neuropathic joints, sarcoidosis and neoplasms may be similar, but can be distinguished from those of osteoarticular tuberculosis. ${ }^{6,14-16}$

A prolonged course of antituberculous drugs is the basis of treatment. Surgery is an adjunct to the drugs and was not required in our patients. Debridement and curettage may be indicated in non-healing lesions. Resection of a destroyed or sequestrated phalanx or metatarsal is rarely necessary. ${ }^{1}$

The radiological evidence of healing includes a decrease in osteoporosis with repair of scalloped lesions and focal sclerosis. In our patients who had substantial loss of a phalanx, healing was characterised by reappearance of the bone mass.

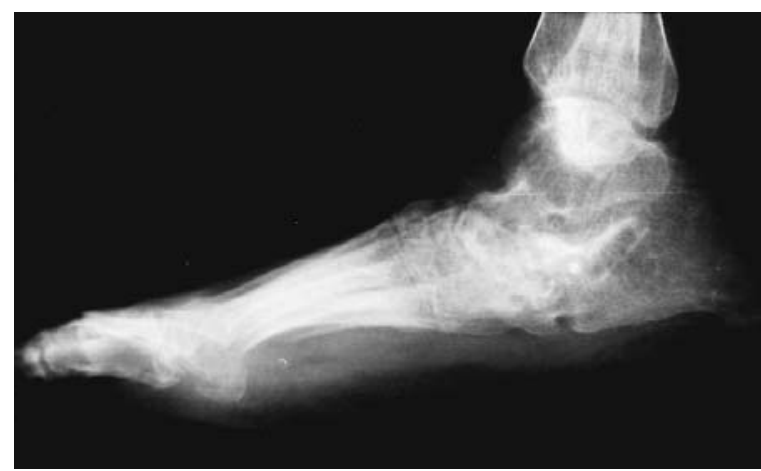

Fig. 6

Radiograph showing loss of the longitudinal arch in a rheumatoid type of lesion.

The rheumatoid type of lesion often showed loss of the medial longitudinal and transverse arches of the foot (Fig. 6 ) with healing. This was probably due to destruction of the intertarsal ligaments and tarsal bones. Misshapen bones and stiffness of the intertarsal ligaments cause loss of shape and suppleness of the foot. If bony ankylosis has not occurred, walking on uneven surfaces often becomes painful despite no active infection in the area. Discomfort or pain in the foot impairs function and triple arthrodesis may be required. Treatment of cystic lesions restored a painless normal gait. Subperiosteal lesions had a similar outcome. For the kissing type of lesion we had variable results depending on the site and the amount of destruction before adequate treatment had commenced. The bony swelling of spina ventosa may persist for a long time and may not always resolve after treatment.

Tuberculosis should be suspected in cases of long-standing pain in the foot, especially in endemic areas. Unlike pulmonary lesions, bone and joint tuberculosis should be treated with antituberculous drugs for more than nine and preferably for 18 months. ${ }^{10}$ Surgery should be reserved only for lesions which fail to heal after adequate chemotherapy.

No benefits in any form have been received or will be received from a commercial party related directly or indirectly to the subject of this article.

\section{$\underline{\text { References }}$}

1. Tuli SM. Tuberculosis of the skeletal system (bones, joints, spine and bursal sheaths). Second ed. New Delhi: Jaypee Brothers Medical Publishers (P) Ltd, 1991:3-122.

2. Dhillon MS, Sharma S, Gill SS, Nagi ON. Tuberculosis of bones and joints of the foot: an analysis of 22 cases. Foot Ankle 1993;14: 505-13.

3. Martini M, Adjrad A. Tuberculosis of the ankle and foot joint. In: Martini M, ed. Tuberculosis of the bones and joint. Berlin, etc: Springer Verlag, 1988.

4. Evanchick CC, Davis DE, Harrington TM. Tuberculosis of peripheral joints: an often missed diagnosis. J Rheumatol 1986;13:187-9.

5. Messner RP. Arthritis due to mycobacteria, fungi and parasites. In: McCarty DJ, Koopman WJ, eds. Arthritis and allied conditions: textbook of rheumatology. Vol 2. Philadelphia, etc: Lea and Febiger. 1993:2035-46.

6. Hsu SH, Sun JS, Chen IH, Liu TK. Reappraisal of skeletal tuberculosis: role of radiological imaging. J Formos Med Assoc 1993;92: 34-41. 
7. Newton P, Sharp J, Barnes KL. Bone and joint tuberculosis in Greater Manchester 1969-1979. Ann Rheum Dis 1982;41:1-6.

8. Hunt DD. Problems in diagnosing osteoarticular tuberculosis. JAMA 1964;190:95-8.

9. Berney S, Goldstein M, Bishko F. Clinical and diagnostic features of tuberculous arthritis. Am J Med 1972;53:36-42.

10. Watts HG, Lifeso RM. Current concepts review: tuberculosis of bone and joints. J Bone Joint Surg [Am] 1996;78-A:288-98.

11. Versfeld GA, Solomon A. A diagnostic approach to tuberculosis of bones and joints. J Bone Joint Surg [Br] 1982;64-B:446-9.
12. Edeiken J, Dalinka M, Karasick D. Edeiken's roentgen diagnosis of diseases of bone. Fourth ed. Baltimore: Williams and Wilkins, 1990.

13. Sobel E, Levitz S. Tuberculosis of the foot: a diagnostic challenge. $J$ Am Podiatr Med Assoc 1995;85:83-90.

14. Wolfgang CL. Tuberculosis joint infection. Clin Orthop 1978;136: 257-63.

15. Davidson PT, Horowitz I. Skeletal tuberculosis: a review with presentations and discussion. Am J Med 1970;48:77-84.

16. Cohen-Sobel E, Levitz SJ, Caselli M, Reilly K, Levitz SJ. Monoarthritic ankle pain, a diagnostic challenge. J Am Podiatr Med Assoc 1994;84:71-6. 